\title{
PENGGUNAAN POTENTIALLY INAPPROPRIATE MEDICATIONS (PIMS) PADA PASIEN GERIATRI RAWAT INAP OSTEOARTHRITIS DI RS PKU MUHAMMADIYAH YOGYAKARTA
}

\section{POTENTIALLY INAPPROPRIATE MEDICATIONS (PIMs) USE AMONG ELDERLY HOSPITALIZED PATIENTS WITH OSTEOARTHRITIS AT PKU MUHAMMADIYAH YOGYAKARTA GENERAL HOSPITAL}

\author{
Andi Namirah Muh. Syuaib AS ${ }^{1}$, Endang Darmawan ${ }^{1}$, Mustofa $^{2}$ \\ ${ }^{I}$ Fakultas Farmasi, Universitas Ahmad Dahlan \\ Jl Prof. Dr. Soepomo, Janturan, Yogyakarta Telp. (0274) 379418 \\ ${ }^{2}$ Fakultas Kedokteran, Universitas Gadjah Mada \\ Email: nami.nugraha@gmail.com
}

\begin{abstract}
ABSTRAK
Penggunaan obat yang tidak tepat (PIMs) pada geriatri merupakan masalah kesehatan masyarakat yang serius karena secara intrinsik terkait dengan peningkatan morbiditas, mortalitas, dan biaya kesehatan. Tujuan penelitian ini adalah untuk mengetahui hubungan antara jumlah obat yang diresepkan, dan durasi rawat inap dengan penggunaan PIMs pada pasien geriatri rawat inap osteoarthritis (OA) di RS PKU Muhammadiyah Yogyakarta. Penelitian ini merupakan penelitian analitik observasional dengan studi cross- sectional. Beers Criteria 2012 digunakan untuk mengidentifikasi penggunaan PIMs pada pasien geriatri rawat inap osteoarthritis. Analisis regresi logistik digunakan untuk mengetahui hubungan jumlah obat yang diresepkan dan durasi rawat inap dengan penggunaan PIMs. Hasil penelitian menunjukkan bahwa 7 (38,9\%) dari total 18 pasien geriatri rawat inap OA teridentifikasi menggunakan PIMs dan dan semua pasien hanya menerima satu PIM. PIMs yang paling umum digunakan adalah estazolam $(11,1 \%)$ dan metoklopramid $(11,1 \%)$. Pada penelitian ini, polifarmasi adalah faktor prediktor utama penggunaan PIMs $(p=0,049)$.
\end{abstract}

Kata kunci: Potentially Inappropriate Medications, Beers Criteria 2012, Geriatri, OA

\begin{abstract}
Potentially inappropriate medications (PIMs) use among elderly is a serious public health problem because it is intrinsically linked to increased morbidity, mortality, and healthcare costs. This study aims to determine the association between number of drug prescribed, duration of hospital stay and PIMs use among elderly hospitalized patients at PKU Muhammadiyah Yogyakarta General Hospital. This study was analytic observational with cross-sectional study. Beers criteria 2012 were used to identify PIMs use among elderly hospitalized patients with osteoarthritis. Logistic regression analysis were used to determine association between number drugs of prescribed, duration of hospital stay and PIMs use. The results showed that 7 (38.9\%) out of 18 hospitalized elderly patients were identified PIMs use and all of patients received atleast one PIM. The most common agents involved in PIMs were estazolam (11.1\%), and metoclopramide (11.1\%). Polypharmacy is a major predictor factor of PIMs use in this study.
\end{abstract}

Keywords: Potentially Inappropriate Medications, Beers Criteria 2012, Elderly, OA 


\section{PENDAHULUAN}

Populasi geriatri di Indonesia tahun 2010 diperkirakan mencapai 23.992 .553 jiwa atau sekitar $9.77 \%$. Jumlah ini akan terus meningkat, hingga diperkirakan pada tahun 2020 mencapai 28.822 .879 jiwa atau $11.34 \%$. Propinsi Daerah Istimewa Yogyakarta, pada tahun 2005 mempunyai jumlah penduduk lanjut usia 3.893.000 jiwa atau $12.48 \%$. Propinsi Daerah Istimewa Yogyakarta adalah propinsi yang memiliki distribusi lanjut usia paling banyak di Indonesia (Mulyaningsih, 2010).

Perubahan fisiologi terkait usia lanjut menyebabkan perubahan farmakokinetik dan farmakodinamika obat pada pasien geriatri. Pasien geriatri memiliki komorbiditas lebih banyak dan sering menerima resep polifarmasi (Momin et al., 2013). Istilah polifarmasi merujuk pada penggunaan beberapa obat, lima macam atau lebih. Barubaru ini, polifarmasi digunakan untuk menggambarkan penggunaan obat-obat yang tidak tepat (PIMs) atau melebihi indikasi klinisnya. Prevalensi pengunaan obat-obat yang tidak tepat pada geriatri dari kisaran $11.5 \%-62.5 \%$. Konsekuensi dari polifarmasi termasuk reaksi obat yang merugikan dan interaksi, ketidakpatuhan, peningkatan risiko gangguan kognitif, gangguan keseimbangan dan jatuh, peningkatan risiko morbiditas, rawat inap, dan mortalitas.

Dalam sebuah penelitian di Kanada baru-baru ini, menunjukkan bahwa hampir setengah dari $27 \%$ geriatri yang secara teratur menerima lima atau lebih obat mengalami efek samping obat yang membutuhkan penanganan medis (Kwan dan Farrel, 2013). Harugeri et al. (2011), melaporkan 32.2\% dari prevalensi ADR pada geriatri, meningkatkan durasi rawat inap pada $5.9 \%$ pasien geriatri. Peresepan yang rasional sulit dicapai pada pasien geriatri dengan beberapa penyakit penyerta. Pasien geriatri yang menjalani rawat inap karena penyakit kronis seperti osteoarthritis (OA) umumnya memperoleh jumlah peresepan obat lebih banyak selama di rumah sakit sehingga berisiko meningkatkan efek samping obat. Oleh karena itu, menghindari obat yang dianggap tidak tepat adalah salah satu intervensi untuk pilihan pengobatan pada pasien geriatri (Corsonello, 2009). Beers Criteria 2012 merupakan salah satu metode untuk mengukur ketidaksesuaian pengobatan yang mencakup obatobat yang sebaiknya dihindari atau dapat digunakan dengan perhatian khusus pada pasien geriatri usia 65 tahun ke atas. Beers criteria, awalnya dikembangkan pada tahun 1991, dan mulai banyak digunakan sejak saat itu.

Pada tahun 2012, Beers criteria diperbaharui oleh American Geriatric Society (AGS) bekerjasama dengan 11 ahli panel di bidang perawatan geriatri dan farmakoterapi. Beers Criteria 2012 yang telah diperbaharui AGS mengidentifikasi 53 obat berpotensi tidak tepat (PIMs), yang dibagi menjadi 3 kategori: 1). PIMs dan kelas obat yang harus dihindari secara umum pada pasien geriatri, 2). PIMs atau kelas obat yang harus dihindari pasien geriatri dengan penyakit atau sindrom tertentu, dan 3). Obatobat yang digunakan dengan hati-hati pada pasien geriatri (Bhavya dan Torgal, 2014). Terapi obat dapat efektif apabila diberikan dengan tepat sesuai kebutuhan dan kondisi pasien (Januar et al, 2010).

Penelitian tentang Beers Criteria yang dilakukan oleh Page et al (2010), terhadap 389 pasien geriatri rawat inap, melaporkan $27.5 \%$ pasien mendapatkan obat dalam cakupan Beers Criteria, dan $9 \%$ mengalami efek yang tidak dikehendaki. Ma et al (2008) dalam penelitannya, mengkonfirmasi bahwa penggunaan lebih dari 6 obat (polifarmasi) adalah faktor utama yang secara signifikan berhubungan dengan penggunaan PIMs pada pasien geriatri. Peneliti lain melaporkan bahwa $\geq 10$ hari rawat inap dikaitkan dengan kemungkinan peningkatan penggunaan PIMs.

Hal ini disebabkan hubungan proporsional antara lama tinggal (lenght of stay) dan jumlah obat yang digunakan (Harugeri et al., 2010). Berdasarkan hal tersebut, perlu dilakukan penelitian tentang hubungan jumlah obat yang diresepkan dan durasi rawat inap dengan penggunaan PIMs berdasarkan Beers Criteria 2012 pada pasien geriatri rawat inap osteoarthritis di RS PKU Muhammadiyah Yogyakarta. 


\section{METODE PENELITIAN}

\section{Alat Penelitian}

Alat yang digunakan untuk penelitian berupa rekam medik pasien, form pengambilan data, dan daftar Beers criteria 2012.

\section{Bahan Penelitian}

Bahan yang digunakan dalam penelitian adalah data dari rekam medik pasien geriatri yang berusia 65 tahun atau lebih (data sekunder) yang mencakup nama pasien, umur, jenis kelamin, jaminan, lama rawat inap, tanggal masuk dan keluar rumah sakit, diagnosis, dan jumlah peresepan.

\section{Jalannya Penelitian}

\section{Rancangan penelitian}

Penelitian ini adalah penelitian analitik observasional dengan studi crosssectional. Pengambilan data secara retrospektif dengan mengambil data rekam medik pasien geriatri rawat inap dari tahun 2011-2014 yang di diagnosa oleh dokter menderita OA di RS PKU Muhammadiyah Yogyakarta. Penelitian ini telah mendapatkan persetujuan dari komite etik penelitian Universitas Ahmad Dahlan dengan nomor registrasi EA/011501003 tanggal 01/02/15.

\section{Pengambilan sampel}

Pengambilan sampel dilakukan dengan metode purposive sampling, dimana pemilihan sampel ditentukan berdasarkan ciriciri spesifik dan karakteristik tertentu dari sampel yang dianggap mewakili populasi.Sebanyak 18 data kunjungan pasien geriatri yang berusia $\geq 65$ tahun dengan diagnosis OA diperoleh melalui penelusuran komputer menggunakan nomor ICD OA (M19.9).

Data tersebut adalah data total kunjungan pasien selama periode tahun 20112014. Selanjutnya, data kunjungan tersebut digunakan untuk menyeleksi pasien geriatri yang masuk kriteria inklusi dan eksklusi. Dari total 18 kunjungan pasien, se

muanya memenuhi kriteria inklusi dan eksklusi. Penelitian ini adalah penelitian analitik observasional yang hanya menggunakan data sekunder (rekam medik pasien) atau tidak ada intervensi dengan pasien sehingga tidak dilakukan proses informed consent.

\section{Definisi operasional variabel penelitian}

a. Jumlah obat yang diresepkan adalah banyaknya obat yang diterima dan digunakan oleh pasien geriatri selama rawat inap di rumah sakit akibat penyakit tertentu.

Jumlah obat yang diterima pasien dibagi menjadi 2 interval kelas $(<10$, dan $\geq 10$ macam). Satuan banyaknya obat yang diresepkan adalah macam.

b. Durasi rawat inap adalah lamanya waktu yang dibutuhkan pasien selama mendapatkan terapi oleh tenaga kesehatan profesional akibat penyakit tertentu, dimana pasien diinapkan di suatu ruangan di rumah sakit.

Lama rawat inap pasien dibagi menjadi 2 interval kelas ( $<7, \geq 7$ hari). Satuan lamanya rawat inap adalah hari.

c. Potentially inappropriate medications (PIMs) adalah obat-obat yang harus dihindari atau dapat digunakan dengan hatihati pada pasien geriatri yang berusia $>65$ tahun.

Prevalensi kejadian PIMs diperoleh berdasarkan perbandingan antara jumlah pasien yang teridentifikasi PIMs $(n=7)$ dengan total sampel penelitian $(n=18)$ dalam satuan persen (\%). Kejadian PIMs diidentifikasi menggunakan Beers Criteria 2012.

\section{Analisis data}

Data dianalisis menggunakan SPSS versi 20.0. Hubungan variabel bebas (jumlah obat yang diresepkan, dan durasi rawat inap) dengan variabel terikat (penggunaan PIMs) diidentifikasi 


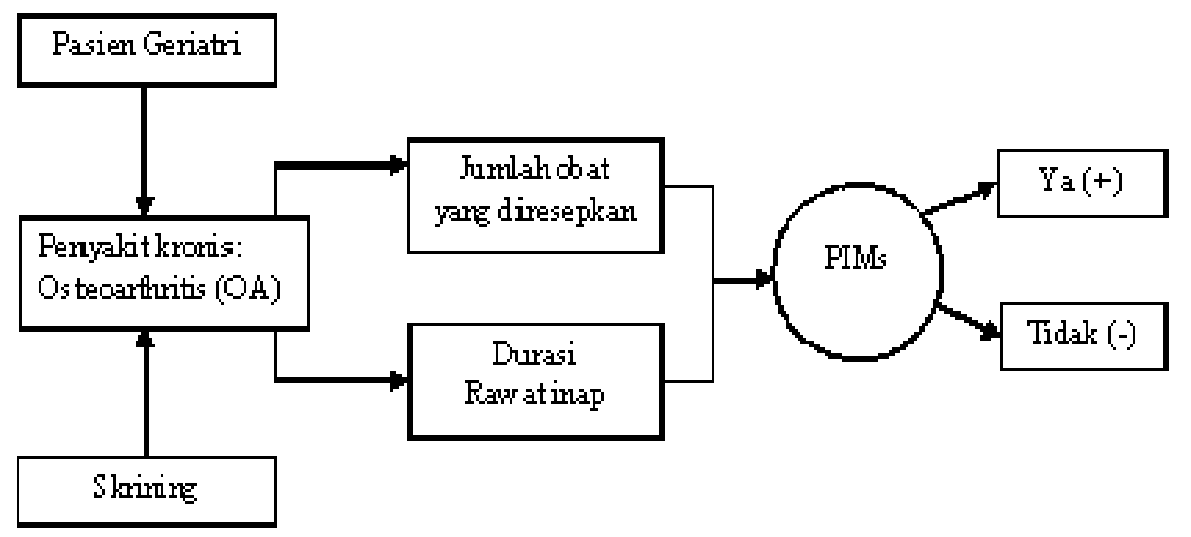

Gambar 1. Desain Penelitian

menggunakan analisis bivariat (Fisher's Exact Test). Nilai $p<0,05$ dianggap signifikan secara statistik.

\section{HASIL DAN PEMBAHASAN}

\section{Prevalensi potentially inappropriate medications}

Sebanyak 18 pasien geriatri rawat inap yang memenuhi kriteria inklusi diikutkan pada penelitian ini. Tabel I menggambarkan secara terperinci demografi sampel penelitian. Hasil identifikasi PIMs menggunakan Beers criteria 2012 diperoleh bahwa dari total 18 pasien geriatri rawat inap dengan diagnosis OA, sebanyak 7 (38.9\%) pasien menggunakan PIMs.

\section{Jenis potentially inappropriate medications}

Estazolam (11.1\%), dan metoklopramid $(11,1 \%)$, adalah PIMs yang paling umum digunakan untuk kategori obat-obat yang harus dihindari secara umum pada pasien geriatri (Tabel II). Penggunaan PIMs untuk kategori obat-obat yang harus dihindari pasien geriatri dengan penyakit atau sindrom tertentu, dan obatobat yang digunakan dengan hati-hati pada pasien geriatri, tidak ditemukan pada penelitian ini. Dari total 18 pasien geriatri rawat inap dengan OA, sebanyak 7 (38.9\%) pasien menerima 1 macam PIM (Tabel III). American Geriatrics Society (2012), menjelaskan bahwa semua jenis benzodiazepin (short dan long acting) dapat meningkatkan risiko gangguan kognitif, delirium, jatuh, fraktur, dan kecelakaan bermotor pada geriatri. Selain itu, geriatri sensitif terhadap benzodiazepin dan cenderung memiliki metabolisme yang lambat terhadap golongan benzodiazepin aksi panjang sehingga meningkatkan risiko efek sampingnya.

Pada beberapa kasus yang berhubungan dengan gangguan tidur pasien, terapi non farmakologi (sleep hygiene) direkomendasikan untuk mengatasi problem medik pasien tersebut, bila terapi non farmakologi ini tidak efektif, maka terapi farmakologi menjadi pilihan. Beberapa obat alternatif yang aman dan efektif bisa digunakan diantaranya adalah zolpidem $(\leq 5$ $\mathrm{mg} / \mathrm{hari}$ ), trazodon, mirtazapin dan doksepin (dosis rendah).

Bila obat alternatif tersebut tidak tersedia di rumah sakit, maka perlu dilakukan penurunan dosis obat benzodiazepin hingga $1 / 2$ dari dosis lazim, selanjunya ditappering dan dihentikan. Selama penggunaan obat benzodiazepin, harus dilakukan monitoring efek samping obat (fungsi kognitif, kewaspadaan, riwayat jatuh, ataxia) serta durasi terapi diperpendek (Holt, 2010).

Food and Drug Association (2007), melaporkan bahwa penggunaan metoklopramid sebagai antiemetik pada geriatri berisiko menyebabkan efek ekstrapiramidal 
Tabel I. Gambaran karakteristik pasien geriatri rawat inap OA di RS PKU Muhammadiyah Yogyakarta periode tahun 2011-2014

\begin{tabular}{lcc}
\hline Karakteristik pasien & \multicolumn{2}{c}{ Jumlah pasien (\%) } \\
\cline { 2 - 3 } & Sampel $(\mathbf{n = 1 8})$ & PIMs (n=7)* \\
\hline Jenis Kelamin & & \\
Laki-laki & $\mathbf{4}(\mathbf{2 2 , 2})$ & $\mathbf{2}(\mathbf{5 0 , 0})$ \\
Perempuan & $14(77,8)$ & $5(35,7)$ \\
Usia (tahun) & & \\
$<75$ & $7(38,9)$ & $2(28,6)$ \\
$\geq 75$ & $11(61,1)$ & $5(45,5)$ \\
Jaminan & & \\
Askes & $\mathbf{1 0}(\mathbf{5 5 , 6})$ & $\mathbf{5}(\mathbf{5 0 , 0})$ \\
Non Askes & $8(44,4)$ & $2(25,0)$ \\
Jumlah obat yang diresepkan (macam) & & \\
$<10$ & $11(61,1)$ & $2(18,2)$ \\
$\geq 10$ & $7(38,9)$ & $5(71,4)$ \\
Durasi rawat inap (hari) & & \\
$<7$ & $10(55,6)$ & $2(20,0)$ \\
$\geq 7$ & $8(44,4)$ & $5(62,5)$ \\
\hline
\end{tabular}

*Identifikasi penggunaan PIMs

menggunakan Beers criteria 2012

Tabel II. Frekuensi penggunaan PIMs (Beers criteria 2012) pada 18 pasien geriatri rawat inap OA di RS PKU Muhammadiyah Yogyakarta

\begin{tabular}{|c|c|c|}
\hline & Frekuensi (N) & $\%$ \\
\hline \multicolumn{3}{|c|}{$\begin{array}{l}\text { Obat-obat yang dihindari secara umum pada geriatri } \\
\text { (Independent of diagnosis) }\end{array}$} \\
\hline \multicolumn{3}{|c|}{ Antikolinergik } \\
\hline \multicolumn{3}{|l|}{ Antiparkinson } \\
\hline Triheksifenidil & 1 & 5,6 \\
\hline \multicolumn{3}{|l|}{ Anxiolitik (Benzodiazepin) } \\
\hline \multicolumn{3}{|l|}{ Short dan Intermediate acting } \\
\hline Alprazolam & 1 & 5,6 \\
\hline Estazolam & 2 & 11,1 \\
\hline \multicolumn{3}{|l|}{ Long acting } \\
\hline Diazepam & 1 & 5,6 \\
\hline \multicolumn{3}{|l|}{ Sistem Syaraf Pusat (SSP) } \\
\hline \multicolumn{3}{|l|}{ Antipsikotik } \\
\hline Haloperidol & 1 & 5,6 \\
\hline \multicolumn{3}{|l|}{ Gastrointestinal (GI) } \\
\hline Metoklopramid & 2 & 11,1 \\
\hline \multicolumn{3}{|c|}{ Obat-obat melebihi dosis yang direkomendasikan } \\
\hline Digoxin $>0,125$ mg/hari & 1 & 5,6 \\
\hline Doxepin $>6 \mathrm{mg} / \mathrm{hari}$ & 1 & 5,6 \\
\hline Spironolakton $>25 \mathrm{mg} /$ hari & 1 & 5,6 \\
\hline
\end{tabular}

Tabel III. Presentasi PIMs (macam PIMs) pada 18 pasien geriatri rawat inap OA di RS PKU Muhammadiyah Yogyakarta

\begin{tabular}{ccc}
\hline Macam PIMs (Beers criteria 2012) & Jumlah pasien (n) & \% PIMs \\
\hline a. 1 macam & 7 & 38,9 \\
b. 2 macam & 0 & 0 \\
\hline
\end{tabular}


termasuk tardive dyskinesia. Tardive dyskinesia (TD), merupakan gangguan yang berpotensi ireversibel yang ditandai dengan gerakan tak terkendali dari wajah, lidah, atau ekstremitas. Risiko terjadinya TD meningkat dengan durasi pengobatan dan total dosis kumulatif. Orang tua, terutama perempuan usia lanjut serta geriatri dengan kondisi fisik lemah yang paling berisiko mengembangkan TD. Terapi metoklopramid harus dihentikan pada pasien yang mengalami tanda-tanda atau gejala tardive dyskinesia. Tidak ada pengobatan yang diketahui untuk tardive dyskinesia. Namun, pada beberapa pasien gejala dapat dikurangi atau diatasi setelah pengobatan metoklopramid dihentikan. Bila terapi alternatif yang aman dan efektif tersedia, sebaiknya metoklopramid tidak digunakan lagi sebagai antiemetik pada geriatri, kecuali untuk terapi gastroparesis. Terapi alternatif ondansetron dan granisetron dapat menjadi pilihan jika tidak ada kontraindikasi (Anonim, 2012).

\section{Prediktor peresepan yang tidak tepat}

Pada penelitian ini, jumlah obat yang diresepkan (polifarmasi) adalah faktor prediktor utama yang berhubungan dengan PIMs pada pasien geriatri dan sesuai dengan temuan dari beberapa peneliti lain diantaranya Bhavya dan Torgal (2014), menemukan bahwa polifarmasi adalah faktor prediktor utama yang berhubungan dengan PIMs $(p=0,024)$. Penelitian yang dilakukan oleh Lima et al 2013 juga menyimpulkan bahwa polifarmasi berhubungan dengan PIMs $(p<0,001)$.

Namun, hubungan sebab akibat antara polifarmasi dan PIM belum jelas. Dapat dibayangkan, PIM pertama bisa menyebabkan efek samping dimana obat sekunder ditambahkan untuk mengurangi efek samping dari obat pertama, sehingga memunculkan peresepan cascade. Alternatifnya, beberapa obat kategori PIMs masih diperlukan, setelah memperhitungkan risiko dan manfaat, serta kompleksitas kondisi klinis pasien yang memerlukan kombinasi terapi. Penelitian klinis terperinci yang meliputi urutan terapi obat diperlukan untuk memperjelas masalah ini.
Namun demikian, review terapi obat dianjurkan pada pasien yang menerima polifarmasi (6 obat atau lebih), dengan maksud untuk menghindari peresepan yang berlebihan dan efek samping yang tidak diinginkan.

Hasil analisis bivariat (Fisher's Exact Test) menunjukkan bahwa jumlah obat yang diresepkan secara signifikan berhubungan dengan penggunaan PIMs $(p=0,049)$. Pasien yang menerima peresepan 10 macam obat atau lebih (polifarmasi) berisiko 11 kali lebih besar mendapatkan peresepan PIMs dibandingkan yang menerima peresepan $<10$ macam obat (OR, 11,25: 95\% CI 1,19-106,12). Pada penelitian ini, durasi rawat inap tidak berpengaruh secara signifikan terhadap penggunaan PIMs $(p=0,145)$. Parthasarathi et al 2011 dalam penelitiannya juga tidak menemukan hubungan yang signifikan antara durasi rawat inap dengan penggunaan PIMs $(p=0,071)$. Hasil analisis ditampilkan pada Tabel III.

Hasil penelitian ini menunjukkan bahwa prevalensi PIMs pada geritari rawat inap OA di RS PKU Muhammadiyah Yogyakarta tergolong tinggi. Faktor utama yang berhubungan dengan penggunaan

\section{KESIMPULAN}

Hasil penelitian ini menunjukkan bahwa prevalensi PIMs pada geritari rawat inap OA di RS PKU Muhammadiyah Yogyakarta tergolong tinggi. Faktor utama yang berhubungan dengan penggunaan PIMs adalah polifarmasi. Pedoman peresepan khusus geriatri diperlukan untuk memberikan informasi kepada dokter dokter tentang efek samping dari obat yang umum diresepkan ketika merawat pasien geriatri. Beers criteria tidak boleh dianggap sebagai pedoman peresepan mutlak, karena dokter selalu memiliki kebebasan untuk memilih obat yang paling tepat untuk pasien mereka.

Selain itu, Beers criteria mungkin tidak sesuai dengan pasien geriatri lokal di Indonesia, ditinjau dari segi farmakokinetik dan farmakodinamik obat yang berbeda. Idealnya, para ahli dalam bidang perawatan geriatri dan farmakologi perlu mempersiapkan kriteria 
eksplisit untuk pasien geriatri di Indonesia dalam upaya untuk menghindari efek samping obat yang merugikan.

\section{KELEMAHAN/KETERBATASAN PENELITIAN}

Beberapa kelemahan/keterbatasan penelitian ini diantaranya: 1). Keterbatasan peneliti untuk mengevaluasi kemungkinan timbulnya efek samping akibat PIMs pada pasien geriatri rawat inap serta kondisi klinis pasien yang sebenarnya tidak dapat di observasi pada penelitian ini karena penelitian ini adalah retrospektif, 2). Ada beberapa data rekam medik fisik pasien yang tidak dapat ditelusuri karena sudah mengalami penyortiran/terselip, sehingga pengambilan data pasien melalui penelusura rekam medik elektronik pasien yang sudah di komputerisasi, 3). Kurang lengkapnya catatan pemberian obat selama pasien di rawat inap merupakan keterbatasan penelitian ini, 4). Beberapa obat dalam daftar Beers criteria 2012 tidak tersedia di Indonesia, sehingga hanya beberapa obat saja yang bisa diidentifikasi pada penelitian ini, dan 5). Beers criteria 2012 belum begitu dikenal luas dikalangan profesional kesehatan, perlu waktu untuk adaptasi untuk mempelajari dan menerapkan metode ini.

\section{UCAPAN TERIMA KASIH}

Kami berterima kasih kepada H. Joko Murdiyanto, Sp.An selaku Direktur Utama RS PKU Muhammadiyah Yogyakarta karena telah mengizinkan kami untuk melakukan penelitian di RS tersebut, Adi Sumartono., Amd yang membimbing kami selama penelitian di RS PKU Muhammadiyah Yogyakarta, Tim Reviewer Jurnal Pharmaciana UAD yang telah mereview jurnal penelitian ini, serta semua pihak-pihak yang telah mensupport penelitian ini.

\section{DAFTAR PUSTAKA}

Anonim, 2012, Potentially Harmful Drugs in Elderly: Beers List, Pharmacist's Letter/Prescriber's Letter, p1-p16.

Anonim, 2012, American Geriatrics Society Update Beers Criteria for Potentially Inappropriate Medication Use in Older Adults: The American Geriatrics Society 2012 Beers Criteria Update Expert Panel, J Am Geriatr Soc, 60: 1532-5415.

Bhavya dan Torgal., 2014, Potentially inappropriate medications in hospitalized elderly patients: a cross sectional study, Int $J$ Basic Clin Pharmacol, 3(1): 215-219.

Corsonello, A., Pranno, L., Garasto, S., Fabietti, P., Bustacchinv, S., dan Lattanzio, F., 2009, Potentially Inappropriate Medicationin Elderly Hospitalized Patients, Drugs Aging J, 26 (1):31-39.

FDA, 2007, NDA metoclopramide: Proposed Risk Evaluation And Mitigation Strategy (REMS), Department Of Health and Human Services.

Harugeri, A., Joseph, J., Parthasarathi, G., Ramesh, M., dan Guidu, S., 2010, Potentially Inappropriate Medication Use in Elderly Patients: A Study Prevalence and Predictors in Two Teaching Hospitals, J Postgrad Med, 56(3): 186191.

Holt, S., Schmiedl, S., dan Thurman, A., 2010, Potentially Inappropriate Medications in the Elderly: The PRISCUS List, $J$ Dtsch Arztebl Int, 107(31-32): 543-51.

Januar, M.G., Ikawati, Z., dan Raharjo, B., 2010, Pengaruh Pemberian Informasi Obat Berdasarkan Beers Criteria Terhadap Pola Pemberian Obat pada Pasien Usia Lanjut Rawat Inap Penyakit Dalam di RSD Prof. Dr. Margono Soekarjo Purwokerto PeriodeMei - Agustus 2010, Makalah disajikan dalam Prosiding 
Seminar Nasional "Eight Start Performance Pharmacist", Yogyakarta, 27 Desember, hal. 20-25.

Kwan, D dan Farrel, B., 2014, Polypharmacy: Optimizing Medication Use In Elderly Patients, Originally published in Pharmacy Practice 2013, 20 April, CGS $J$ of CME; 4(1): 21-26.

Lima, V.T.J., Garbin, C.A.S.., Garbin, A.J.I., Sumida, D.H., dan Saliba, O., 2013, Potentially Inappropriate Medications used by the elderly: prevalence and risk factors in Brazilian care homes, $B M C$ Geriatrics; 13:52.

Momin, T.G., Pandya, R.N., Rana, D.A., dan Patel,V.J., 2013, Use of Potentially Inappropriate Medications in Hospitalized Elderly at A Teaching Hospital: A Comparison Between Beers 2003 and 2012 criteria, Indian J Pharmaco, 45(6): 603-607.

Mulyaningsih, K., Hakim, L., dan Pramantara D.I., 2010, Profil Drug-Related Problems pada Pasien Geriatrik Rawat Inap di
Bangsal Bugenvil Unit Penyakit Dalam RSP. Dr. SardjitoYogyakarta Periode September 2009 - Januari 2010, Makalah disajikan dalam Prosiding Seminar Nasional "Eight Start Performance Pharmacist", Yogyakarta, 27 Desember,hal. 8-14.

Ma, H.M., Lum, C.M., Dai, L.K., Kwok, C.Y.T., dan Woo, J., 2008, Potentially Inappropriate Medication in elderly patients in outpatient clinics, Asian $J$ of Gerontol Geriatr; 3(1):27-33.

Page, R.L., Linnebur, S.A., Bryant, L.L., dan Ruscin, J.M., 2010, Inappropriate in the hospitalized elderly patient: Defining the problem, evaluation tools, and possible solution, Dove Medical Press, J Clin Intervention in Aging, 5: 75-87.

Parthasarathi, G., Harugeri A., Joseph J., Ramesh M., dan Guido S., 2011, A Study of Prevalence and Predictors of Potentially Inappropriate Medication Use In Elderly Patients inTwo Indian Teaching Hospitals, J ICIUM, hal. 1-12. 